\title{
Effects of captopril on factors affecting gastric mucosal integrity in aspirin-induced gastric lesions in Sprague-Dawley rats
}

Nafeeza Mohd Ismail', Ibrahim Abdel Aziz Ibrahim², Najihah Binti Mohd Hashim³, Kamsiah Jaarin ${ }^{3}$

'Department of Pharmacology, Faculty of Medicine, Universiti Teknologi MARA, Shah Alam, Malaysia

${ }^{2}$ Department of Pharmacology and Toxicology, Faculty of Medicine, Umm Al-Qura University, Makkah, Saudi Arabia

${ }^{3}$ Department of Pharmacology, Faculty of Medicine, Universiti Kebangsaan Malaysia, Kuala Lumpur, Malaysia

Submitted: 20 September 2011

Accepted: 22 February 2012

Arch Med Sci 2013; 9, 6: 1132-1137

DOI: 10.5114/aoms.2012.31252

Copyright $\odot 2013$ Termedia \& Banach

\section{Abstract}

Introduction: Captopril is an angiotensin-converting enzyme inhibitor, which is used as an antihypertensive agent and has shown antioxidant properties. This study aims at determining the effects of captopril on factors affecting gastric mucosal integrity in aspirin-induced gastric lesions.

Material and methods: Eighteen male Sprague-Dawley (200-250 g) rats that were given aspirin ( $40 \mathrm{mg} / 100 \mathrm{~g}$ body weight) were divided into three groups: the control, captopril ( $1 \mathrm{mg} / 100 \mathrm{~g}$ body weight daily) and ranitidine $(2.5 \mathrm{mg} / 100 \mathrm{~g}$ body weight twice daily) groups. Ranitidine and captopril were given orally for 28 days. Rats in all groups were sacrificed and the parameters measured.

Results: Captopril reduced gastric acidity, and increased gastric glutathione $(\mathrm{GSH})$ and prostaglandin $\mathrm{E}_{2}\left(\mathrm{PGE}_{2}\right)$ significantly in comparison to the control group. Captopril also reduced malondialdehyde (MDA) and gastric lesions insignificantly compared to the control group. Ranitidine healed the lesions significantly compared to the control group. There was no difference between ranitidine and captopril on the severity of lesions, gastric acidity, MDA and GSH. Captopril increased $\mathrm{PGE}_{2}$ compared to ranitidine $(p<0.05)$.

Conclusions: Captopril has desirable effects on the factors affecting gastric mucosal integrity (acidity, $\mathrm{PGE}_{2}$ and GSH) and is comparable to ranitidine in ulcer healing.

Key words: captopril, ranitidine, aspirin, gastric lesions.

\section{Introduction}

Non-steroidal anti-inflammatory drugs (NSAIDs), with their broad analgesic, anti-inflammatory and antipyretic effects, are among the most frequently used drugs because pain, inflammation, and pyrexia are so common. Approximately 30 million people worldwide are prescribed NSAIDs daily [1]. Additionally, the use of NSAIDs is gradually increasing, mostly because of the expanding aging population [2], which requires frequent administration of NSAIDs to treat conditions such as osteoarthritis, which is common in the elderly [3].

However, the non-selective NSAIDs are well known to cause gastrointestinal mucosal damage and of particular concern are patients with arthritic conditions. Statistics from the Western population have shown

\author{
Corresponding author: \\ Prof. Dr. Nafeeza Mohd Ismail \\ Department of Pharmacology \\ Faculty of Medicine \\ Universiti Teknologi MARA \\ Level 7 - Tower 1 - 12A \\ Science and Technology Complex \\ 40450 Shah Alam, Selangor \\ Malaysia \\ Phone: 603-5544 2884 \\ Fax: 603-5544 2831 \\ E-mail: \\ nafeeza@salam.uitm.edu.my, \\ jjurishi@yahoo.com
}


that about $2 \%$ to $4 \%$ of non-selective NSAID users develop serious gastric mucosal erosions [4] and about $20 \%$ of long-term NSAID users develop peptic ulcers [5]. In addition, about $1 \%$ to $8 \%$ of elderly NSAID users are hospitalized for complications of peptic ulcers within 1 year of initiating therapy [6].

Although the discovery of selective NSAIDs is indeed a breakthrough as it is devoid of gastrointestinal side effects, the use of non-selective NSAIDs is still popular due to their relatively low cost. Therefore, studies exploring the possibilities to preserve gastric mucosal integrity during treatment with non-selective NSAIDs are still much needed [7].

The mechanism of how NSAIDs induce gastric lesions remains unclear and cannot be explicitly explained. The most probable mechanism suggests disruption of gastric mucosal integrity via the production of free radicals [8]. The body has endogenous antioxidants, which under normal conditions are adequate to protect the organs. In situations that differ from normal such as exposure to noxious stimuli, vulnerable organs such as the lung, liver and stomach need a high level of endogenous antioxidants such as non-protein sulfhydryls (mainly reduced glutathione) to maintain their integrity. In such situations, exogenous antioxidants may prove to be beneficial [9]. The NSAIDs also inhibit the production of protective prostaglandins, which is another possible mechanism in the pathogenesis.

Captopril is the earliest angiotensin-converting enzyme (ACE) inhibitor [10]. It is commonly used as an antihypertensive drug. It contains a sulfhydryl group and recently this sulfhydryl containing ACE inhibitor is reported to exhibit the ability to scavenge free radicals and provide protection against free radical mediated oxidative damage [11]. In addition, captopril is also reported to be structurally similar to the enzyme kininase II [12]. Have to explain on kininase II in relation to gastric ulcer. As a result, captopril blocks the effect of this enzyme by competitive inhibition and causes a rise in plasma bradykinin levels. Accumulation of bradykinin is known to raise the production of prostaglandins, as reported in previous studies $[13,14]$.

In an attempt to find a new avenue to minimize gastric mucosal damage due to aspirin, this study was carried out to investigate the effects of captopril on the healing of gastric lesions, levels of gastric acidity, prostaglandin $\mathrm{E}_{2}\left(\mathrm{PGE}_{2}\right)$ and glutathione $(\mathrm{GSH})$, as well as lipid peroxidation.

\section{Material and methods}

Eighteen male Sprague-Dawley rats (200-250 g) were randomly assigned to three groups. Group I (6 rats) was a control group, group II (6 rats) was a positive control treated with ranitidine, and group III (6 rats) was treated with captopril. At the begin- ning of the study, rats from all groups were challenged with a single dose of aspirin $(40 \mathrm{mg} / 100 \mathrm{~g}$ body weight) to induce gastric lesions. Treatment was initiated $6 \mathrm{~h}$ after induction. The ranitidine group was given $2.5 \mathrm{mg} / 100 \mathrm{~g}$ body weight ranitidine twice daily and the captopril group was given $10 \mathrm{mg} / \mathrm{kg}$ body weight captopril once a day. After 28 days of treatment, all rats were deprived of food and housed in cages with a wide mesh wire bottom for $24 \mathrm{~h}$ to prevent coprophagy. The rats were killed on the $29^{\text {th }}$ day and the severity of gastric lesions was assessed. The other parameters measured were gastric acidity, gastric tissue contents of malondialdehyde (MDA), $\mathrm{PGE}_{2}$ and GSH. This study was approved by the Ethics Committee for animal studies, Faculty of Medicine, Universiti Kebangsaan Malaysia (UKM), Kuala Lumpur, Malaysia.

\section{Measurement of gastric acidity}

The lower end of the oesophagus and pylorus were clamped and the stomach removed. Samples of gastric juice were collected and centrifuged at 3000 r.p.m. for $10 \mathrm{~min}$. Aliquots for each sample were titrated with $0.01 \mathrm{~N} \mathrm{NaOH}$ to a $\mathrm{pH}$ of 7.0. The hydrogen ion concentration was calculated as described by Shay et al. [15].

\section{Assessment of gastric lesions}

The gastric mucosa was exposed by cutting the stomach along the greater curvature, washing with saline and laying it on a flat wooden board. The macroscopic assessment of aspirin-induced gastric lesions was performed by an independent examiner who was blinded to the supplementation that the rats had received. The assessment of lesions was made according to a semi-quantitative scale described earlier by Berry et al. [16] but which has since been modified by Ismail et al. [17]. The modified scale used was as follows: 5 = continuous lesions that occupied almost the entire length of the gastric fold, $4=$ lesions which occupied almost $80 \%$ of the entire fold, 3 = presence of multiple lesions that measured 1-4 $\mathrm{mm}$ in length on $80 \%$ of the folds, 2 = presence of at least two lesions approximately $2 \mathrm{~mm}$ in length, $1=$ presence of a single lesion with or without generalized erythema, 0.5 = presence of dot haemorrhages; and $0=$ no visible damage.

\section{Measurement of gastric malondialdehyde content}

Tissue samples weighing $0.2 \mathrm{~g}$ from the corpus region were homogenized using a glass homogenizer (Potter S: B Braun, Germany). The content of gastric tissue MDA was then determined using the method described by Ledwozyw et al. [18]. The gastric tissue content of protein was determined by the Lowry method [19] and the MDA was expressed in terms of as $\mathrm{nmol} / \mathrm{mg}$ protein. 


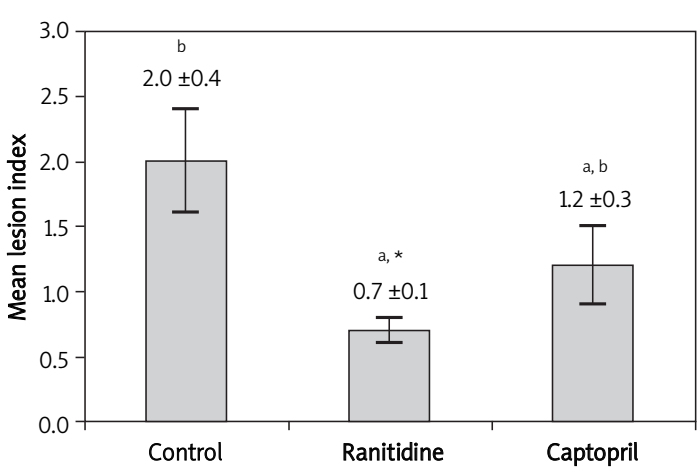

Figure 1. Effects of captopril and ranitidine treatments for 28 days on gastric lesion index in rats $a, b$ The same letters of the alphabet indicate that the values are not significantly different, and different letters of the alphabet indicate that the values are significantly different

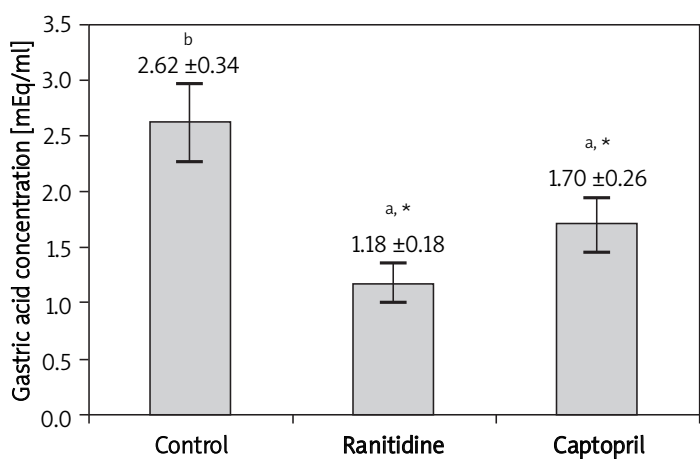

Figure 2. Effect of captopril and ranitidine on gastric acidity in rats subjected to aspirin-induced gastric lesions

a,b Same letters of the alphabet indicate that the values are not significantly different, and different letters of the alphabet indicate that the values are significantly different

\section{Measurement of gastric prostaglandin $\mathrm{E}_{2}$ content}

Samples of gastric mucosal tissue were prepared for $\mathrm{PGE}_{2}$ analysis according to the method described by Redfern et al. [20]. The tissue samples were homogenized in 20 volumes of $100 \%$ ethanol using a glass homogenizer on ice. Cold water was added to this mixture to make the concentration of $15 \%$ ethanol. The mixture was then centrifuged at $400 \times G$ for $10 \mathrm{~min}$. The supernatant obtained was transferred to another tube and $10 \mathrm{ml}$ of acetic acid was added to make a pH of 3.0. The extraction of $\mathrm{PGE}_{2}$ was performed using an Amprep C18 cartridge (Amersham International, UK) and the content was analyzed using a commercial kit (Prostaglandin $\mathrm{E}_{2}{ }^{125}$ assay system: Amersham International, UK).

\section{Measurement of gastric glutathione content}

Gastric GSH content was measured using a wellestablished method [20]. The gastric tissue sam- ples were homogenized in 4 volumes of (5\% TCA/ $0.01 \mathrm{~N}) \mathrm{HCl}$ and centrifuged at $17000 \times \mathrm{g}$ for $15 \mathrm{~min}$ at $2^{\circ} \mathrm{C}$. The supernatant was separated for GSH assay. The ratio of reduced glutathione to oxidized glutathione was calculated.

\section{Statistical analysis}

All results were expressed as mean \pm SEM. Statistical analysis was performed using non-parametric tests such as Kruskal-Wallis and Mann-Whitney. A difference with a probability value of less than $5 \%(p<0.05)$ was considered statistically significant for all parameters.

\section{Results}

\section{Effect of captopril and ranitidine on gastric lesions}

The effect of captopril and ranitidine on the severity of gastric lesions is shown in Figure 1. The ranitidine group exhibited a gastric lesion index of about $65 \%$ lower compared to the control group $(p<0.05)$. There was no difference between the captopril and the control groups although the gastric lesion index for the captopril group was numerically lower (40\%) than the control group. There was also no difference between the captopril and the ranitidine groups.

\section{Effect of captopril and ranitidine on gastric acidity}

The effect of captopril and ranitidine on gastric acidity is shown in Figure 2 . The ranitidine treatment significantly reduced the gastric acidity compared to the control group $(p<0.05)$. The ranitidine group showed 55\% lower gastric acidity. There was also a significant reduction of gastric acidity in the captopril compared to the control group $(35 \% ; p<0.05)$. The gastric acidity between the captopril and the ranitidine groups was comparable $(p>0.05)$.

\section{Effect of captopril and ranitidine on gastric malondialdehyde content}

The gastric MDA content for the ranitidine group was $45.7 \%$ lower than the control group ( $p<0.05)$. There was no significant difference between the captopril and the control group. The gastric MDA content for the ranitidine group was 29\% lower than the captopril group, but there was no significant difference between the groups, as shown in Figure 3.

\section{Effect of captopril and ranitidine on gastric prostaglandin $\mathrm{E}_{2}$ content}

The effect of captopril and ranitidine on gastric $\mathrm{PGE}_{2}$ content is shown in Figure 4. Gastric $\mathrm{PGE}_{2}$ con- 


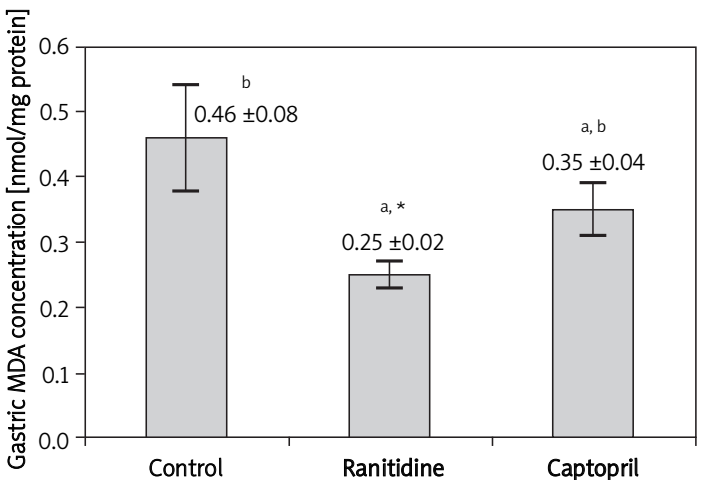

Figure 3. Effect of captopril and ranitidine on gastric MDA content in rats subjected to aspirin-induced gastric lesions

${ }_{a, b}$ Same letters of the alphabet indicate that the values are not significantly different, and different letters of the alpha bet indicate that the values are significantly different

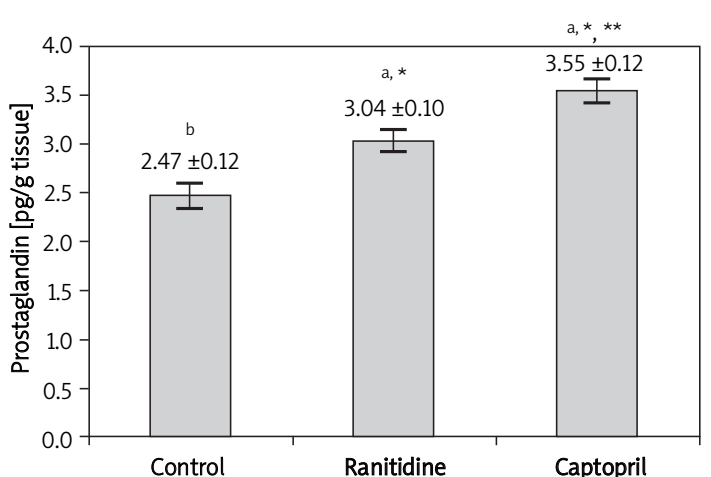

Figure 4. Effect of captopril and ranitidine on gastric $\mathrm{PGE}_{2}$ content in rats subjected to aspirin-induced gastric lesions

$a, b$ Same letters of the alphabet indicate that the values are not significantly different, and different letters of the alphabet indicate that the values are significantly different

tension is twice a day. Our preliminary experiments showed that twice daily dosing of the dosage employed in this study caused the rats to become hypotensive. A daily dosing avoided the drop in blood pressure. Thus the latter dosing frequency was used. Further investigations on different dosages with a twice daily dosing are warranted. Also, the current study demonstrates that ranitidine promotes the healing of lesions from aspirin-induced gastric ulcer. This confirms and extends the previous finding that this histamine $\mathrm{H}_{2}$ receptor antagonist is an effective antiulcer agent [21].

Malondialdehyde is one of the end-products of lipid peroxidation, and the extent of lipid peroxidation is most frequently measured by estimating MDA levels [22]. The current study shows that both ranitidine and captopril reduced the level of gastric MDA content. Surprisingly, only ranitidine was able reduce the MDA significantly compared to the con-

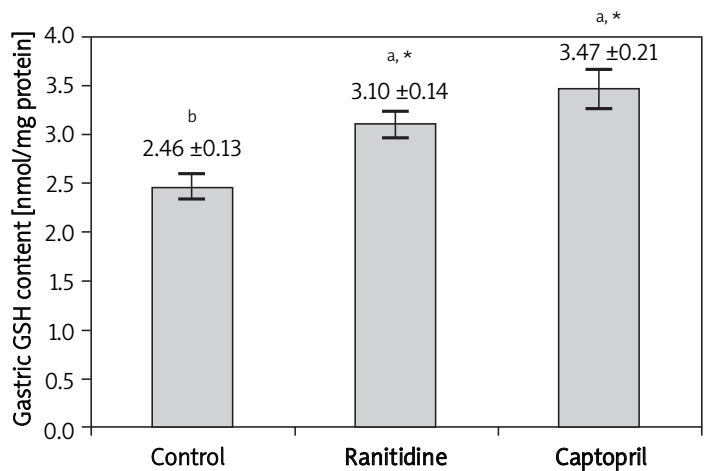

Figure 5. Effect of captopril and ranitidine on gastric GSH content in rats subjected to aspirin-induced gastric lesions

${ }^{a, b}$ Same letters of the alphabet indicate that the values are not significantly different, and different letters of the alphabet indicate that the values are significantly different 
trol. A detailed explanation of this phenomenon is beyond the scope of the current study. Captopril, which exhibited free radical scavenging activities, was expected to retard the lipid peroxidation process, but this was not the case in our study. The probable factors responsible for the lack of this effect could again be the dosing frequency and the duration of the treatment. Furthermore, the free radicals generated by aspirin attacked not only lipid molecules but also DNA, protein and any molecule that has a double bond structure. As a result, measurement of MDA alone is not sufficient to demonstrate the antioxidant properties of ranitidine or to disprove the efficacy of captopril in free radical scavenging.

In contrast to the findings on MDA, we found that another indicator of antioxidant status, the gastric GSH content, was significantly higher in both ranitidine and captopril groups compared to the control group. This finding suggests that captopril, through its sulfhydryl group, is able to scavenge free radicals and this reduced the consumption of reduced GSH. On the other hand, the increment of gastric GSH content in the ranitidine group might be due to the ongoing healing process.

In this study, we found that captopril increased the gastric $\mathrm{PGE}_{2}$ content. This observation is in agreement with previous studies, where most of the increment observed was in other organs such as the kidney [23, 24]. This finding could be due to the accumulation of bradykinin after the inhibition of ACE by captopril. Accumulation of bradykinin enhances biosynthesis of prostaglandins (PGs) [13]. Additionally, another study suggested that sulfhydryl group containing agents encourage the biosynthesis of PGs in the gastric mucosa [25]. Interestingly, we found that ranitidine also increased the gastric $P G E_{2}$ content. An explanation of this event is beyond the scope of the study. Studies to investigate the relation between ranitidine and prostaglandin have to be done.

Gastric acidity is an aggressive factor that ultimately leads to gastric lesions. In the present study, we found that both ranitidine and captopril reduced the gastric acidity effectively. This confirms and extends previous findings that ranitidine, a histamine $\mathrm{H}_{2}$ receptor antagonist, is an effective antisecretory agent [26]. The inhibition of gastric acidity by captopril is via increasing gastric $\mathrm{PGE}_{2}$ content. Captopril is reported to be structurally similar to enzyme kininase II. As a result, captopril blocks the effect of the enzyme by competitive inhibition and causes a rise in plasma bradykinin levels. Accumulation of bradykinin raises the production of prostaglandins. Finally, prostaglandin inhibits gastric acid secretion through the prostaglandin receptor on the membrane of parietal cells in the stomach $[27,28]$. Besides that, the fall in gastric acidity in the captopril group might also be caused by the presence of a sulfhydryl group in the structure of the compound, since agents containing such groups are capable of reducing gastric acidity [29].

In conclusion, we found that administration of captopril at $10 \mathrm{mg} / \mathrm{kg} /$ day for 28 days could not significantly heal the aspirin-induced gastric lesions but produced desirable effects on gastric acidity, $\mathrm{PGE}_{2}$ and $\mathrm{GSH}$. Its capability to increase gastroprotective parameters and at the same time reduce the aggressive acid factor optimises the balance between protective and aggressive factors. In view of this linkage, we strongly suggest captopril as a potential novel antiulcer agent.

\section{References}

1. Maiden L. Capsule endoscopic diagnosis of nonsteroidal antiinflammatory drug-induced enteropathy. J Gastroenterol 2009; 44 Suppl 19: 64-71.

2. Laine L. Gastrointestinal effects of NSAIDs and coxibs. J Pain Symptom Manage 2003; 25 (2 Suppl): S32-40.

3. Hegazy R, Alashhab M, Amin M. Cardiorenal effects of newer NSAIDs (Celecoxib) versus classic NSAIDs (Ibuprofen) in patients with arthritis. J Toxicol 2011; 2011: 862153.

4. Goldstein JL, Larson LR, Yamashita BD, Boyd MS. Management of NSAID-induced gastropathy: an economic decision analysis. Clin Ther 1997; 19: 1496-509.

5. Naesdal J, Brown K. NSAID-associated adverse effects and acid control aids to prevent them: a review of current treatment options. Drug Saf 2006; 29: 119-32.

6. Griffin MR. Epidemiology of nonsteroidal anti-inflammatory drug-associated gastrointestinal injury. Am J Med 1998; 104 (3A): 23S-9S.

7. Gupta M, Eisen GM. NSAIDs and the gastrointestinal tract. Curr Gastroenterol Rep 2009; 11: 345-53.

8. Hawkey CJ. The gastroenterologist's caseload: contribution of the rheumatologist. Semin Arthritis Rheum 1997; 26 (6 Suppl 1): 11-5.

9. Saad QHM, Kassim NM, Top GM, Ismail NM. Tocotrienol rich fraction and its efects on parameters affecting gastric mucosal integrity after a single exposure to indomethacin. Pakistan J Nutr 2002; 1: 89-92.

10. Hawkey CJ, Karrasch JA, Szczepański L, et al. Omeprazole compared with misoprostol for ulcers associated with nonsteroidal antiinflammatory drugs. omeprazole versus misoprostol for NSAID-induced Ulcer Management (OMNIUM) Study Group. N Engl J Med 1998; 338: 727-34.

11. Valcheva-Kuzmanova S, Krasnaliev I, Galunska B, Belcheva A. Influence of DL-alpha-tocopherol acetate on indomethacin-induced gastric mucosal injury in rats. Auton Autacoid Pharmacol 2007; 27: 131-6.

12. Ondetti MA, Rubun B, Cushman DW. New frontier in cardiovascular therapy. In: Sonnenblick EH, Laragh JH, Lesch $M$ (eds.). Focus on angiotensin converting enzyme inhibition, angiotensin converting enzyme inhibitors: discovery and development. Exerpta Medica 1989.

13. Tamba M, Torreggiani A. Free radical scavenging and copper chelation: a potentially beneficial action of captopril. Free Radic Res 2000; 32: 199-211.

14. Waeber B, Brunner HR, Brunner DB, Curtet AL, Turini GA, Gavras H. Discrepancy between antihypertensive effect and angiotensin converting enzyme inhibition by captopril. Hypertension 1980; 2: 236-42.

15. Shay H, David CH, Gruenstein M. A quantitative method for measuring spontaneous gastric secretion in the rat. Gastroenterology 1954; 26: 906-13. 
16. Berry CN, Prouteau M, Lloyd KG. Sulphasalazine and PhCL28A inhibit the formation of ethanol- and phenylbutazone-induced rat gastric ulcers: lack of involvement of endogenous prostaglandins? Br J Pharmacol 1988; 93: 465-72.

17. Ismail NM, Jaarin K, Ahmad A, Marzuki A, Ng WK, Gapor MT. Palm vitamin $E$ and the healing of ethanol induced gastric lesions. Asia Pac J Clin Nutrition 1999; 8: 258-62.

18. Ledwozyw A, Michalak J, Stepień A, Kadziołka A. The relationship between plasma triglycerides, cholesterol, total lipids and lipid peroxidation products during human atherosclerosis. Clinical Clinica Acta 1986; 155: 272-84.

19. Lowry OH, Rosebrough NJ, Farr AL, Randall RJ. Protein measurement with the Folin phenol reagent. J Biol Chem 1951; 193: 265-75.

20. Redfern JS, Lee E, Feldman M. Effect of indomethacin on gastric mucosal prostaglandins in humans. Correlation with mucosal damage. Gastroentrology 1987; 92: 969-77.

21. Griffith OW. Determination of glutathione and glutathione disulfide using glutathione reductase and 2-vinylpyridine. Anal Biochem 1980; 106: 207-12.

22. Lazzaroni M, Sainaghi M, Bianchi Porro G. Non-steroidal anti-inflammatory drug gastropathy: clinical results with antacids and sucralfate. Ital J Gastroenterol Hepatol 1999; 31 Suppl 1: S48-53.

23. Moore TJ, Crantz FR, Hollenberg NK, et al. Contribution of prostaglandins to the antihypertensive action of captopril in essential hypertension. Hypertension 1981; 3: 168-73.

24. McGiff JC, Terragno NA, Malik KU, Lonigro AJ. Release of a prostaglandin E-like substance from canine kidney by bradykinin. Circ Res 1972; 31: 36-43.

25. Konturek SJ, Brzozowski T, Piastucki I, Radecki T, Dupuy D, Szabo S. Gastric mucosal protection by agents altering gastric mucosal sulfhydryls. Role of endogenous prostaglandins. Digestion 1987; 37: 67-71.

26. Jensen RT, Collen MJ, McArthur KE, et al. Comparison of the effectiveness of ranitidine and cimetidine in inhibiting acid secretion in patients with gastric hypersecretory states. Am J Med 1984; 77: 90-105.

27. Miller TA. Protective effects of prostaglandins against gastric mucosal damage: current knowledge and proposed mechanisms. Am J Physiol 1983; 245: G601-23.

28. Cryer B, Feldman M. Effects of nonsteroidal anti-inflammatory drugs on endogenous gastrointestinal prostaglandins and therapeutic strategies for prevention and treatment of nonsteroidal anti-inflammatory drug-induced damage. Arch Intern Med 1992; 152: 1145-55.

29. Liu JL, Zhang XJ, Wang CC. The role of sulfhydryls in indomethacin-induced gastric mucosal injury in rats. Sheng Li Xue Bao 1989; 41: 523-8. 